\title{
Techno-Economic Comparative Assessment of Asvt Versus Conventional Sub-stations for Rural Electrification
}

\author{
Kitheka Joel Mwithui ${ }^{1}$, David Murage ${ }^{1}$, Michael Juma Saulo ${ }^{2}$ \\ ${ }^{1}$ Department of Electrical and Electronic Engineering, Jomo Kenyatta University of Agriculture and Technology, Nairobi, Kenya \\ ${ }^{2}$ Department of Electrical and Electronic Engineering, Technical University of Mombasa, Mombasa, Kenya \\ Email address: \\ kithekajoelmwithui@tum.ac.ke (K. J. Mwithui),dkmurage25@yahoo.com (D. Murage), michaelsaulo@tum.ac.ke (M. J. Saulo)
}

\section{To cite this article:}

Kitheka Joel Mwithui, David Murage, Michael Juma Saulo. Techno-Economic Comparative Assessment of Asvt Versus Conventional Substations for Rural Electrification. American Journal of Electrical Power and Energy Systems. Vol. 5, No. 2, 2016, pp. 11-16. doi: 10.11648/j.epes.20160502.11

Received: April 7, 2016; Accepted: April 16, 2016; Published: May 3, 2016

\begin{abstract}
The overall electricity access rate is still very low in most sub-Saharan African (SSA) countries. The rate is even lower in rural areas where most of the population in these countries lives. In Kenya about $8 \%$ of rural communities lives at close proximity to High voltage transmission lines yet they have no electricity. One of the main obstacles to rural electrification (RE) is the high cost of laying the distribution infrastructure owing to the dispersed nature of loads and low demand. Thus, electrifying the rural areas needs to be considered holistically and not just on the financial viability. To reduce cost, it is important that auxiliary service voltage transformer (ASVT) sub-station, which are cheaper than the conventional sub-station be explored. This research aimed at carrying out the techno-economic assessment of Auxiliary service voltage transformer sub-station and the conventional sub-station that can be used to step down $132 \mathrm{kv}$ supply from transmission line to $240 \mathrm{v}$ to supply single phase loads in rural areas where there is no any nearby conventional sub-station but there are trunks of high voltage transmission lines at close proximity. The research further explored the maximum number of ASVT sub-stations that can be terminated on $132 \mathrm{kv}$ within a specified distance beyond which it would be economically viable to use a conventional sub-station. In this research local prices and the life cycle costing of sub-stations were used.
\end{abstract}

Keywords: Auxiliary Service Voltage Transformer (ASVT), Techno-Economic Assessment (TEA), Transmission Line (TL), Life Cycle Costing (LCC), Conventional Sub-station (CS)

\section{Introduction}

Many people in rural areas in developing countries do not have access to electricity and even electrification of the metropolitan areas and suburbs is incomplete or unreliable. It has been reported that more than 1.6 billion people, mostly in developing countries, do not have access to electricity and that most of them live in rural areas. This trend is even highly pronounced in rural areas of Sub-sahara Africa. [1, 2]

The high rate of low power connectivity has been amplified by the low concentration of electricity users and the cost of setting up conventional sub-stations being very high, thus the power utility company cannot generate an adequate return on investment. $[3,5]$, on the other hand there are large number of rural communities living around or in close proximity to high transmission line but are not supplied with electricity. The main obstacle being, these transmission lines have very high voltages that cannot be directly and cheaply be used for electrification. [4, 6]

To address the prohibitive costs incurred with the use of conventional substations, non conventional sub-station namely; Auxiliary Service Voltage transformer (ASVT) substation is explored in this journal.

The auxiliary service voltage transformer also known as station service voltage transformer (SSVT) combines the characteristics of instrument transformer with power distribution capability. In this transformer, the high voltage side is connected directly to the overhead transmission line of either $220 \mathrm{kV}$ or $132 \mathrm{kV}$, while the secondary side may be of typical voltage ratings of $240 \mathrm{~V}, 480 \mathrm{~V}, 600 \mathrm{~V}$ or any other voltage level supplies designed on order. One step down principle is applied to achieve the low voltages just like in instrument transformers $[7,8]$. 
The Auxiliary service voltage transformer can either be used with its low voltage output to directly supply needed power near transmission lines or simply step up the ASVT low voltage output through distribution transformer for a local distribution network.

In developing countries where transmission line infrastructure is already in place but a wide spread distribution infrastructure is lacking, the non conventional distribution substation technologies can be used to greatly reduce the electrification costs for small villages [4].

\section{The Auxiliary Service Voltage Transformer}

The ASVT, sometimes known as a station service voltage transformer (SSVT) is insulated in sulfur hexafluoride (SF6) gas and combines the characteristics of instrument transformer with power distribution capability [9]. All the dielectric characteristic of the conventional instrument transformer are applicable to ASVT even though these are hybrid apparatus which are between an instrument transformer and a distribution transformer. These transformers fulfill the standards for both types, i.e. IEEEC 57.13.1993 and IEEE C57.12.00 [10]. This inductive transformer has a very high thermal power in comparison with conventional instrument transformer, in general from 20 up to 60 times more than the design of new generation, without reaching the capacity of a power transformer. [8]

The ASVT is capable of tapping either $220 \mathrm{kv}$ or $132 \mathrm{kv}$ and step it down to $240 \mathrm{v}$ in one step. This eliminates the number of transformers required to step down high voltage using the conventional method i.e. $132 \mathrm{kv} / 66 \mathrm{kv} / 33 \mathrm{kv} / 11 \mathrm{kv}$, hence cutting the cost required to set up ASVT sub-station. [10, 12].

ASVTs were originally designed to suit supply for auxiliary services within the sub-station such as lighting loads, motor loads and instrument purposes [11]. In developing countries where transmission lines infrastructure is already in place but a wide spread distribution infrastructure is lacking, the ASVT sub-station technologies can be used as a compact transformer to greatly reduce the electrification cost for rural electrification. The ASVT can be used to supply loads directly with its low voltage or simply step up the ASVT low voltage output through distribution transformer for local distribution network.

Tapping the high voltage transmission line and connecting an ASVT with a small foot print sub-station will provide affordable, readily available electricity to many rural dwellers in close proximity to high voltage lines and presently without power [11].

\subsection{The Penetration Point of Asvt Sub-station on $132 \mathrm{kv}$ Transmission Line}

A research was carried out to investigate whether termination of the ASVT sub-station on $132 \mathrm{kv}$ transmission line could lead to violation of the voltage profile of the line. The point of ASVT termination was also varied to investigate whether there was a specific penetration point of the ASVT sub-station that was to be adhered to. The researcher further investigated whether variation of the of the $132 \mathrm{kv}$ transmission line from $440 \mathrm{KM}$ to $600 \mathrm{KM}$ could lead to violation of the transmission line voltage profile. The study results were as shown in Fig. 1 graph. [13]

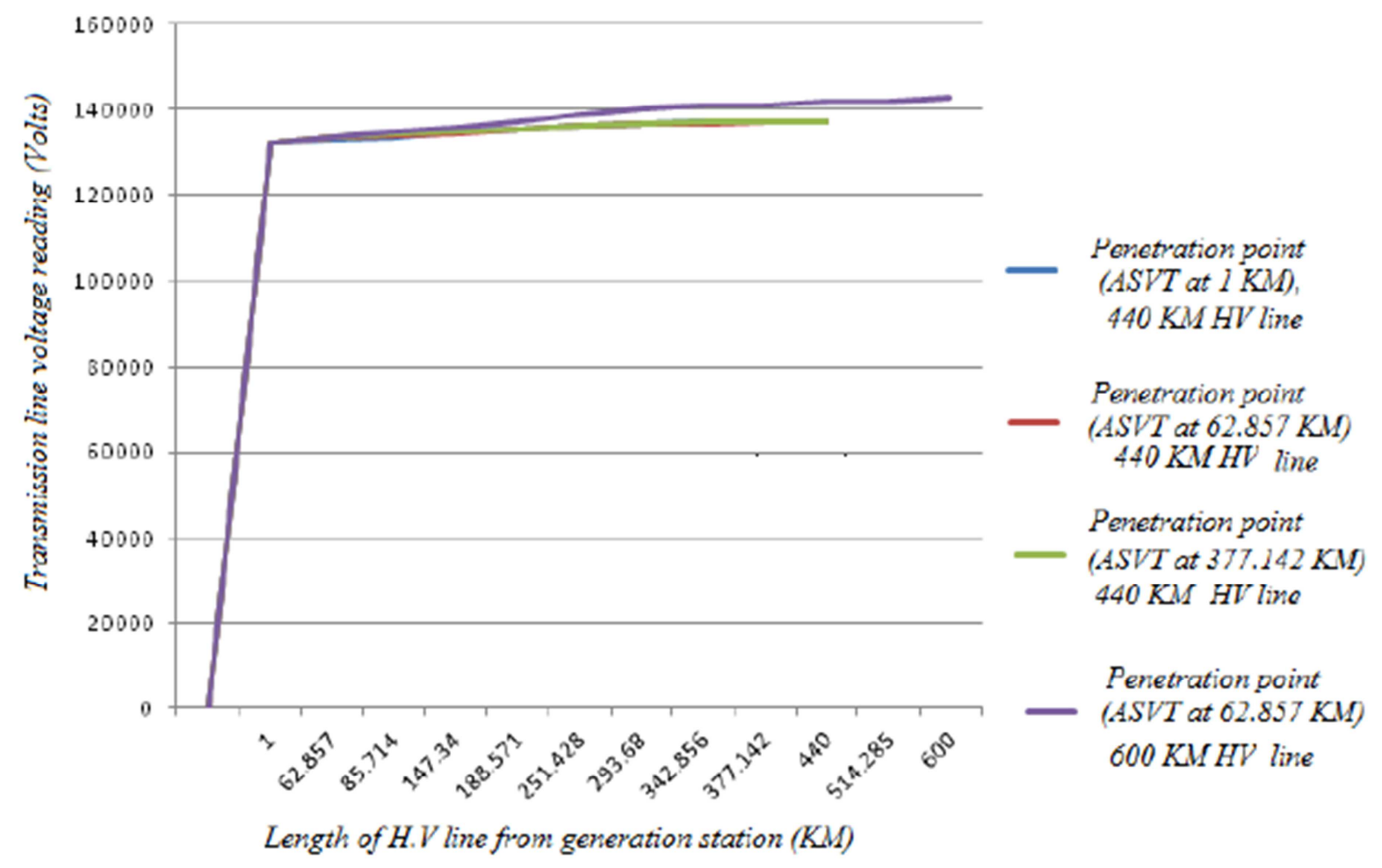

Fig. 1. Penetration point of ASVT sub-station on $132 \mathrm{kv}$ transmission line. 
The above study revealed that the ASVT sub-station can be terminated from any point of the $440 \mathrm{KM}, 132 \mathrm{kv}$ transmission line without the violation of the line voltage profile. This was a positive realization in the fact that the termination of the ASVT sub-station would depend on the location of the village at close proximity to the H.V line.

Further study was carried out to investigate whether a longer transmission line would lead to voltage profile violation. This line was increased to $600 \mathrm{KM}$. This lead to violation of the transmission line as displayed by blue line in Fig. 1. The voltage profile was to be maintained at $\pm 6 \%$ of the transmission line voltage.

\subsection{The Optimum Penetration Level of Asvt Sub-station on $132 k v$ Transmission Line}

A further study was carried out to investigate the maximum number of ASVT sub-stations that can be terminated on a $440 \mathrm{KM}, 132 \mathrm{kv}$ transmission line without voltage profile violation.

The results were as captured in Fig. 2. [8]

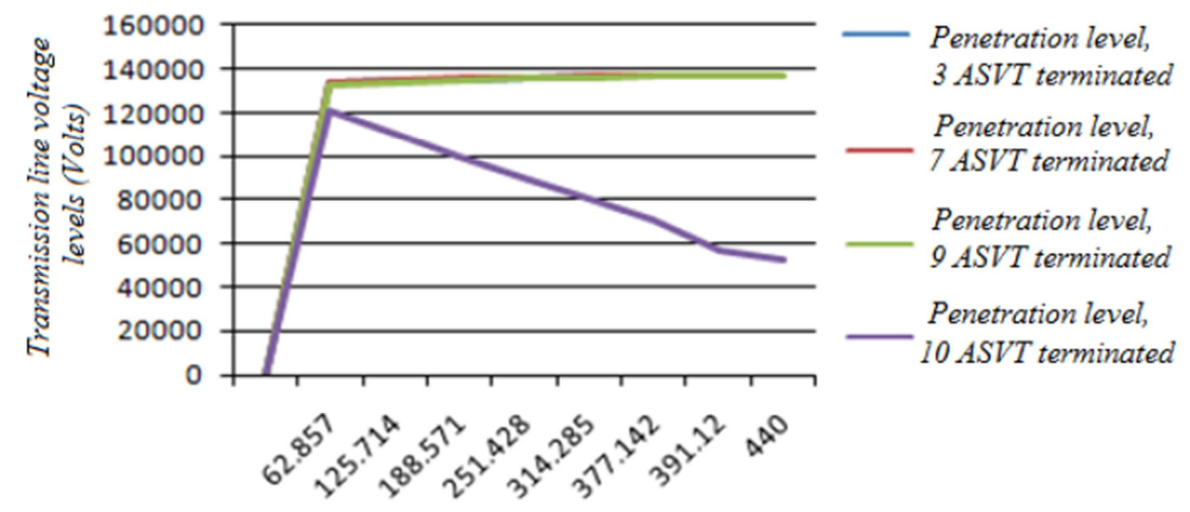

Length of $\mathrm{HV}$ line from generation station (KM)

Fig. 2. The penetration level of AVST sub-station on $132 \mathrm{kv}$ transmission line.

The ASVT sub-stations were terminated on the 440KM, $132 \mathrm{kv}$ transmission line then the voltage profile of the line was monitored.

When 3, 7, 9 ASVT sub-stations were terminated on the $132 \mathrm{kv}$ line, the transmission line voltage as maintained within $132 \pm 6 \% \mathrm{kv}$, Which is the Kenya Power and Lighting Company recommended transmission line voltage profile.

When the tenth ASVT sub-station was terminated, the transmission line voltage levels reduced drastically as captured by the blue line of Fig. 1 .

This showed that the surge impedance loading of the transmission line was affected which led to violation of the line voltage profile.

\section{Methodology}

\subsection{Asvt Sub-station to Supply Maungu Village}

A case study of Maungu village located along Nairobi Mombasa highway was used to analyze the cost of setting up an ASVT sub-station to supply the village. The features of the village are as follows: [13]

(i) Has 18 households and a shopping centre.

(ii) Located 300 metres from the $132 \mathrm{kv}$ transmission line

(iii) $40 \mathrm{KM}$ away from the conventional sub-station.

(iv) Sparsely populated.

(v) The village is not supplied with electricity.

The ASVT sub-station tap power directly from the over head transmission lines through high voltage connectors without interrupting the power flow.
The ASVT sub-station use one transformer and a bus bar to interconnect transformers. A disconnector switch and a circuit breaker are required, but to further reduce the cost of components the circuit breaker can be replaced by a disconnector switch.

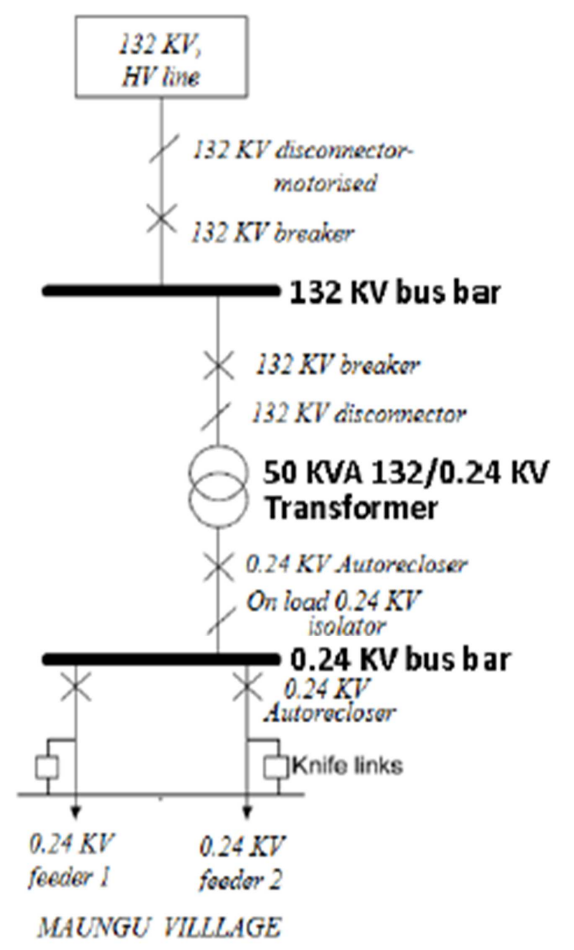

Fig. 3. $132 / 0.24 \mathrm{kV} A S V T$ sub-station single line diagram. 


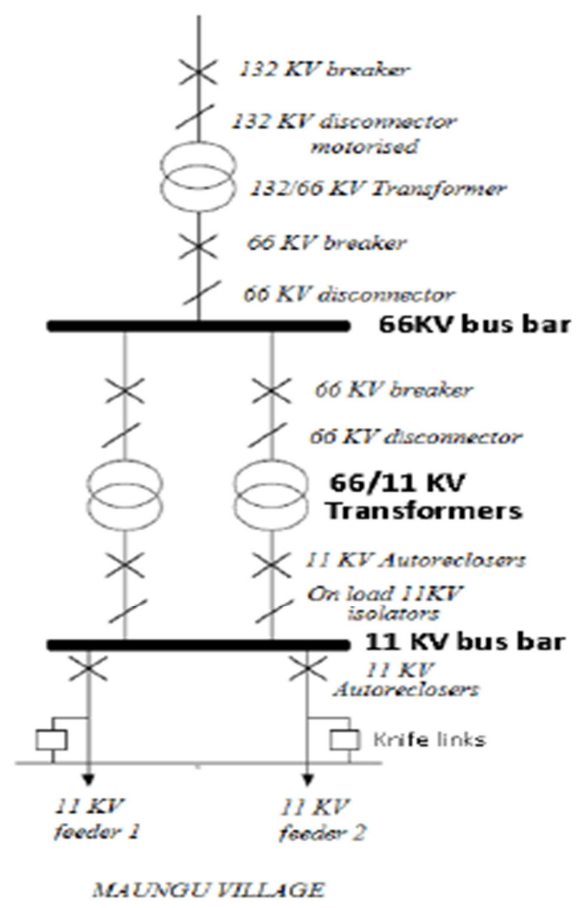

Fig. 4. 132/66/11kv conventional sub-station single line diagram.

The ASVT sub-station removes all the back up that is found in the conventional sub-station and as such when one component of the sub-station fails customers will definitely experience power outage. This is not a serious problem to the customers in the rural villages in comparison to having no electricity supply as long as the cost of electricity connection is affordable. [14]

The ASVT sub-station single line diagram is as shown in Fig. 3 and ASVT sub-station layout in Fig. 5.

\subsection{Conventional Sub-station to Supply Maungu Village}

Another study was carried out to assess the cost to be incurred to set up and maintain a conventional sub-station to supply Maungu village.

A conventional sub-station is a fully flashed sub-station that terminates the transmission line and as a result maintains a high level of service.

A conventional sub-station is designed with a large amount of redundancy in terms of transformers, disconnect switches, circuit breakers, bus bars in order to provide continued operation under failure or high load.

This distribution sub-station has many components involved, thus being very large and spreads over large ground area. A single line diagram of the conventional sub-station is as shown in Fig. 4.

\subsection{Life Cycle Costing of Sub-stations.}

A life-cycle cost analysis (LCC) is geared at determining the total cost of a sub-station and expenses incurred in maintaining it.

The main reasons for carrying out LCC analysis are: [14]

(i) Comparison of the costs incurred in setting up a substation.

(ii) To determine the most cost-effective sub-station.

The life cycle costing of ASVT sub-station and conventional sub-station were carried out. The study considered the prices of the equipment required to set up the sub-station, its protection and one year equipment.

The local prices were considered and in cases where the equipment were not locally available, the quotation prices used by Kenya power and lighting company (KPLC) were used.

The techno-economic comparative assessment of ASVT versus conventional sub-station is tabulated in table 1. [13]

The life-cycle cost of a project can be calculated using the formula:

$$
\mathrm{LCC}=\mathrm{C}+\mathrm{Mpw}+\mathrm{Epw}+\mathrm{Rpw}-\mathrm{Spw}
$$

Where;

$\mathrm{C}=$ capital cost of a project i.e. initial capital expense for the equipment, the system design, engineering, and installation.

$\mathrm{M}=$ maintenance i.e. is the sum of all yearly scheduled operation and maintenance $(\mathrm{O}$ and $\mathrm{M})$ costs.

$\mathrm{Pw}=$ the present worth of each factor.

$\mathrm{E}=$ Energy cost of the system i.e. the sum of the yearly fuel cost.

$\mathrm{R}=$ replacement cost i.e. the sum of all repair and equipment replacement cost anticipated over the life of the system.

$\mathrm{S}=$ salvage value of a system i.e. its net worth in the final year of the life-cycle period.

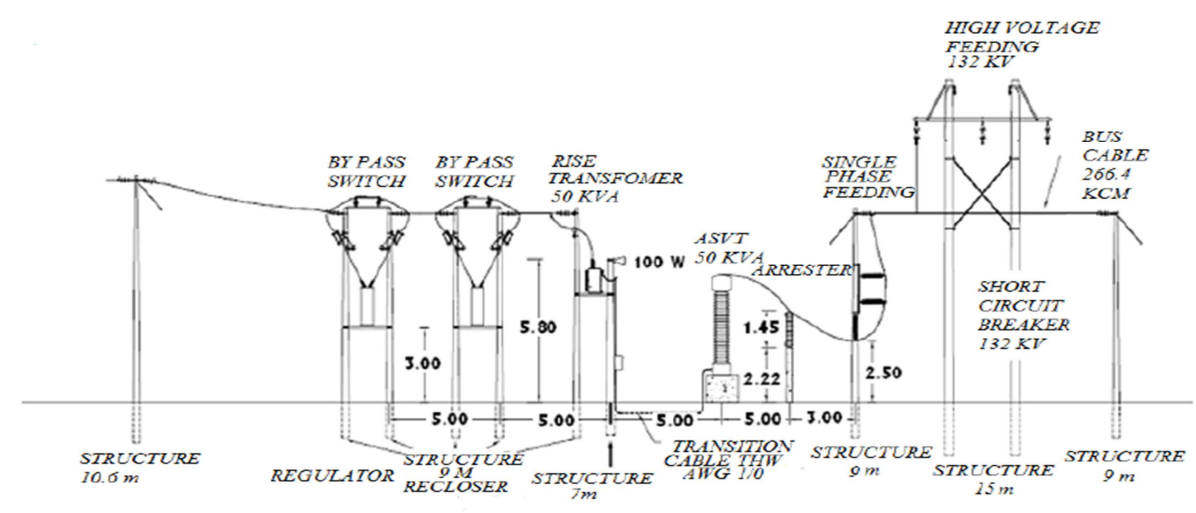

Fig. 5. ASVT sub-stations layout. 
Table 1. Life cycle costs foe a fully flashed conventional versus ASVT sub-station.

\begin{tabular}{|c|c|c|c|c|c|}
\hline \multirow{2}{*}{$\begin{array}{l}\text { PARTICULARS } \\
\text { CAPITAL (C) } \\
\end{array}$} & \multirow[b]{2}{*}{ PRICE PER ITEM (Kshs) } & \multicolumn{2}{|c|}{$\begin{array}{l}\text { CONVENTIONAL } \\
\text { SUB-STATION }\end{array}$} & \multicolumn{2}{|c|}{ ASVT SUB-STATION } \\
\hline & & Quantity & Total Price (Kshs.) & Quantity & Total Price (Kshs.) \\
\hline $132 \mathrm{kv}$ disconnector switch motorized & 300,000 & 2 & 600,000 & 1 & 300,000 \\
\hline $132 \mathrm{kv}$ breaker & $1,250,000$ & 2 & $2,500,000$ & 1 & $1,250,000$ \\
\hline $66 \mathrm{kv}$ disconnector switch & 300,000 & 3 & 900,000 & & \\
\hline $66 \mathrm{kv}$ breaker & $1,250,000$ & 3 & $3,750,000$ & & \\
\hline $66 \mathrm{kv}$ busbar & $1,600,000$ & 1 & $1,600,000$ & & \\
\hline $\mathrm{ON}$ load $11 \mathrm{kv}$ isolator & 225,000 & 3 & 675,000 & & \\
\hline 240V busbar & 100,000 & & & 1 & 100,000 \\
\hline $240 \mathrm{~V}$ recloser & $1,000,000$ & & & 3 & $3,000,000$ \\
\hline $\mathrm{ON}$ load $240 \mathrm{~V}$ isolator & 225,000 & & & 1 & 225,000 \\
\hline Knife link & 58,000 & 2 & 116,000 & 2 & 116,000 \\
\hline $11 \mathrm{kv}$ busbar & 100,000 & 1 & 100,000 & & \\
\hline $11 \mathrm{kv}$ tie bar & 100,000 & 1 & 100,000 & & \\
\hline Civil works & & & $4,000,000$ & & $2,000,000$ \\
\hline Earthing & & & $1,750,000$ & & 750,000 \\
\hline 132/66kv, 10MVA Transfomer & $50,000,000$ & 1 & $50,000,000$ & & \\
\hline 66/11kv. 5MVA Transformer & $49,000,000$ & 2 & $98,000,000$ & & \\
\hline SUB-TOTAL & & & $115,911,000$ & & $56,841,000$ \\
\hline \multicolumn{6}{|l|}{ Operation and maintenance (M) } \\
\hline Transformer and switch gear service (per year) & $15,000,000$ & 2 & $30,000,000$ & 1 & $15,000,000$ \\
\hline SUB-TOTAL & & & $115,911,000$ & & $56,841,000$ \\
\hline \multicolumn{6}{|l|}{ REPLACEMENT (RPw) (per year) } \\
\hline ON load kv isolator & 225,000 & 3 & 675,000 & 1 & 225,000 \\
\hline $66 \mathrm{kv}$ breaker & $1,250,000$ & 3 & $3,750,000$ & & \\
\hline $66 \mathrm{kv}$ breaker & $1,250,000$ & 3 & $3,750,000$ & & \\
\hline SUB-TOTAL & & & $4,425,000$ & & $1,475,000$ \\
\hline \multicolumn{6}{|l|}{ SALVAGE (SPw) (per year.) } \\
\hline $20 \%$ of original & & & $6,954,660$ & & $2,500,000$ \\
\hline SUB-TOTAL & & & $6,954,000$ & & $2,500,000$ \\
\hline
\end{tabular}

\subsection{Results and Discussion}

Fig. 3 and 4 shows single line diagram of ASVT and conventional sub-station technologies respectively. Table 1 displays the life cycle cost analysis of both conventional and ASVT sub-stations. The cost of setting up a conventional sub-station to supply Maungu village with electricity is kshs. 196,481,340 (1,926,284 Us Dollars) while the cost of setting up an ASVT sub-station to supply the same village with electricity is kshs.70,816,000 (694,274 Us dollars).

From table 1, it was observed that ASVT sub-station is three times cheaper than the conventional sub-station.

The research also intended to identify the maximum number of ASVT sub-stations that can be used to supply villages in close proximity to high voltage transmission line with electricity beyond which a conventional sub-station will be more economically viable.

\subsection{Research Recommendation}

The techno-economic comparative assessment of the nonconventional sub-stations should be carried out to draw conclusion on the most economically viable nonconventional sub-station that can be used to supply Maungu village with electricity and the power utility company realize return on investment.

\section{Conclusion}

The data analysis of table 1 led to a conclusion that it is more economical to set up ASVT sub-station to supply Maungu village with electricity than to set up a conventional sub-station to supply the same village with electricity.

The life cycle cost comparative assessment of table 1 also led to a conclusion that a maximum of three ASVT sub-stations can be used to supply electricity to villages living at close proximity to $132 \mathrm{kv}$ transmission line for a stretch of $40 \mathrm{KM}$, beyond which a conventional sub-station will be more economically viable.

\section{References}

[1] World energy outlook, SBN: 978-92-6412413-4.

[2] G. Dagbjartsson, C. Gaunt., 'Rural electrification,' A scoping report, 2013.

[3] M. Saulo, M. Mbogho, "Implication of capacitor coupling substation on rural electrification planning in kenya," in Procceedings of 3rd international Kenya Society of Electrical and Electronics Engineers Conference, KSEEE, 2014.

[4] M. J. Saulo, Penetration level of unconventional rural electrification technologies on power networks. PhD thesis, University of Capetown, May 2014. 
[5] M. Saulo, C. Gaunt, M. Mbogho, 'Comparative assessment of capacitor coupled substation and auxiliary service voltage transformer for rural electrification' in 2nd Annual International Conference in Kabaraka University, 2012.

[6] R. Gomez, A. Solano, C. Gaunt, 'Rural electrification project development, using auxiliary service voltage transformer," pp. $1-6,2010$.

[7] Arteche Instrument Transformer Manual (2010): ASVT245 and ASVT-145 manual and technical brochures.

[8] Kitheka J. Saulo J. Murage D. 'Determination of the penetration level of ASVT sub-station on $132 \mathrm{kv}$ line without voltage profile violation.' International Journal of energy and power engineering vol 5-1, pp 22-28, Feb 2016.

[9] Omboua A. Application report "the high voltage line becomes a power distributor: A successful test in Congo - Brazzaville" Congo. 2006.

[10] Omar C., Gomez R. Solano A. Acosta E. (2010) Eradicating energy poverty "Rural Electrification in Chuahua, Mexico at one third of the cost versus a conventional substation" Mexico.

[11] Saulo M. J, Gaunt C. T "implication of using Auxiliary Service Voltage Transformer substation for Rural Electrification." International journal of energy and power engineering. Vol 4-1) pp 1-11. 2014.

[12] Kitheka J. Saulo J. Murage D. 'The penetration level of Auxiliary service voltage transformer sub-station on a power network for rural electrification,' in Kabarak University $5^{\text {th }}$ Annual conference, July 2015.

[13] Kitheka J. 'The optimum penetration level of Auxiliary service voltage transformer sub-station on $132 \mathrm{kv}$ transmission line without voltage profile violation.,' Msc thesis, JKUAT, 2016.

[14] G. Anderson, K. Yanev, 'Non conventional substation and distribution system for rural electrification," in 3rd IASTED Africa PES 2010, 2010. 